

\title{
Complexity of Iterative Model - Architectural Integrated Design as an Evolutive Transdisciplinary Strategy. Case Study: A City Without a River
}

\author{
Bujar Bajçinovci ${ }^{1}$, Florina Jerliu ${ }^{1 *}$ \\ ${ }^{1}$ University of Prishtina, "UP", Faculty of Civil Engineering and Architecture, Kosovo. \\ "Emails:bujar.bajcinovci@uni-pr.edu,florina.jerliu@uni-pr.edu
}

\begin{abstract}
Contemporary challenges should encourage new explorations, in order to administer new urban solutions, thus, assuring better and higher quality of life. The meaning of transdisciplinary design consists of different professions closely related to the architectural design, targeting for better and qualitative design solutions, which with new findings exceed the conventional and traditional disciplinary barriers. The study presented in this paper investigated the down town of Prishtina city, focussing on urban design issues, pollution, ecology, and sustainable urban design. The research method consists of empirical observation through wide centre zone, with an accent to the urban water management plan, as a contemporary reflection to the past decisions of Prishtina municipality. Furthermore, the conceptual findings from the results of this research, will show the need and necessity of adopting the contemporary design strategies, thus, reflecting and recommending the implementation of an integrated problem solving strategies. By consolidating the new design strategies as a new integrated system into the existing urban municipality guidelines, it is expected to have a significant positive impact in the communities by raising the quality of life in Prishtina.
\end{abstract}

Keywords: Architecture, Integrated design, Transdisciplinary, River, Sustainability

\section{INTRODUCTION}

There is real cause for concern about the well-being of nature, and environment. Negative phenomena are reflected on our health, natural resources, economic, recreational and aesthetic occurrences. In general, it is hard to implement maxims of sustainability because of the difficulties that often accompany them: conflict of interests, market activities, private interests of users. Hence, most environmental premises often end's in the sphere of interest of enthusiasts, aesthetic activities or the concern of naturalists. New challenges should thus stimulate new research and should be directed at the exploitation of all resources in order to achieve the better quality of life. The architecture in terms of its activities and programs, 
aim to participate in transdisciplinary problem solutions, which can contribute more appropriate in aiming to achieve the better quality of life. The new millennium brings a new way and new style of life, as a result of many complex circumstances. So, we come to the situations, when we wonder about the necessity of redefining many of actual life habits [10].

Currently, we can state that there is a certain gap between academic knowledge and architectural practice, or, the principles of integrated design strategies have not been adequately implemented in design practice. Hence, there is no quality of integration in the conceptual design, there is only few reflections of the overall system, which makes it very tempting and by limited efforts to implement those principles on fundamental design projects. However, there is no consolidated information of who are the real obstacles, or difficulties to implement above cited design strategies. Which are, the simple obstacles of integration? [10].

"Our design process is such that only pieces are optimized and not the whole. Each of these professionals is designing fully within the silo of their discipline, and the interaction between each discipline is usually kept to a minimum ... The optimization of the building's individual systems is primarily done in isolation, based on rule-of-thumb conventions that target abstract, generalized standards. These systems are then assembled into a building" [1].

\section{MATERIALS AND METHODS}

\section{Process Description}

Ancient cultures, without the use of the word "ecology" were built with ecology in mind, otherwise the phenomena will bring social disintegration, disaster and ruin. It can be noted that the need can create harmony between the necessity's and the genius idea in certain environments and situations. One from its genesis respected and valued environment in which he dwells, with emphasis in finding harmony and symbiosis between his needs and nature [10].

Biology has studied how organisms and living communities are built. "But it is no less important to understand what such living systems know, in a broad sense; that is, what they remember (what agent-object sign relations are biologically preserved?), what they recognize (what distinction they are capable and not capable of?), what signs they explore (how they communicate, make meaning and use signs?) and so on. These questions are all about how different living systems perceive the world, what experience motivates what actions, based on those perceptions" [2] ... "Man's specific environment is not situated in 
the universal environment like content in its container. A living being is not reducible to a meeting point of influences. Whence the inadequacy of any biology which, through complete submission to the spirit of the physicochemical sciences, would eliminate from its domain every consideration of meaning. A meaning, from the biological and psychological point of view, is an assessment of values in keeping with a need" [2] [10].

Humans from beginning respected and valued environment in which they dwell, with emphasis in finding harmony and symbiosis between their needs and the nature, or the Umwelt. The expressions 'collective Umwelt', or 'swarm's Umwelt', should also be in accord, since organism can hardly be modelled as a centralized system [3] [4] [10].

However, the relationship between the Umwelt of organism and the Umwelts of its cells requires further explanation and more detailed analysis. The whole becomes seen through functional circles which, for example, include the body of the (swarm) organism moving together, in one piece [3] [4] [10]. The approach to analysis, and possible explanations of the problem, the following research questions will be used:

- What have we done with the river Prishtevka?

- What are we doing now with the river Prishtevka?

- Why, and what is the benefit?

The essence of transdisciplinary design is still not quite clear whether it is a handful of different professions closely related to the task of designing the best possible solutions, or perhaps activities beyond the usual and conventional boundaries of disciplines with the new knowledge that is not contained in any of the disciplines involved? Currently, we are witnessing a supplementary academic study, furthermore including the creation of new professions in this digital era. Architecture, a profession from its genesis implement interdisciplinary approach, and the necessary process of design by multidisciplinary nature, new era, new concepts, a symbiosis [4] [10].

Jürgen Mittelstraß uses the term in defining 'transdisciplinarity' as a form of research that transcends disciplinary boundaries to address and solve problems related to the life-world. Mittelstraß "argues that transdisciplinarity is primarily a form" of research for addressing and reflecting on issues in the life-world. Against the background of harm and serious risk posed by technologies and growth that does not fit within the disciplinary paradigms of academia, he calls for the transgression of disciplinary boundaries for identifying, structuring and analysing problems in research. [Mittelstraß, 1992], [6]. 
Contrary to the more pragmatic approach of transdisciplinarity as a form of research, others argue for a further intellectual endeavour on a fundamental theoretical level. They conceive of transdisciplinarity as a theoretical unity of all of our knowledge, which they think is needed to respond adequately to knowledge demands for problemsolving in the life-world. [Nicolescu, 1996, Max-Neef, 2005], [6].

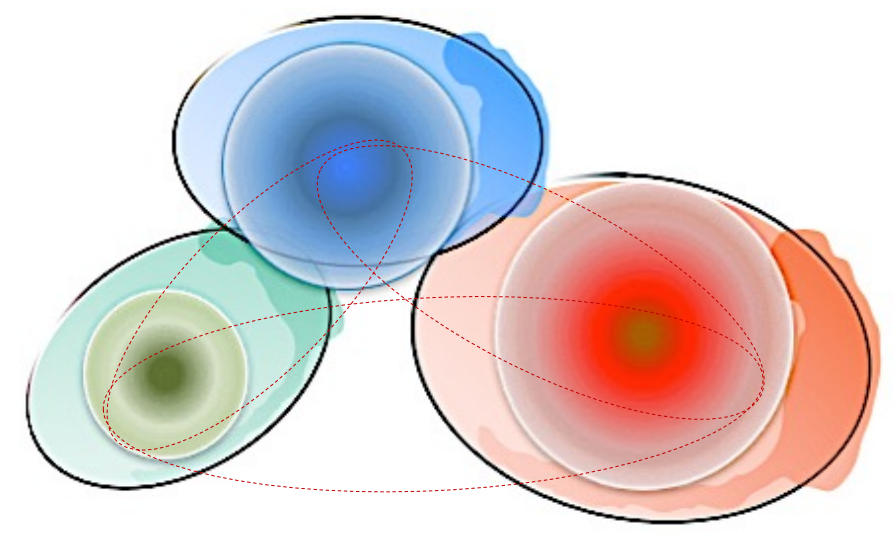

Figure 1. Transformation of system models. [Source: Authors, 2016] [10].

In a world characterized by rapid change, uncertainty and increasing interconnectedness, there is a growing need for science to contribute to the solution of persistent, complex problems [6]. It also includes a focus on real world problems, through collaborative work involving academic and non-academic stakeholders. Transdisciplinary research is therefore "driven by problem solving and integrates perspectives from public agencies, the private sector and civil society in the research process" [5] [6] [4] [10].

In order to define and understand what is meant by 'transdisciplinary research' it is useful first to consider other forms of knowledge product. According to Tress et al. 2006, various approaches in this field provide the following summary of definitions [7], [5]:

Disciplinary: "Process of projects that take place within the bounds of a single, currently recognized academic discipline" [7] [5] [10]. 


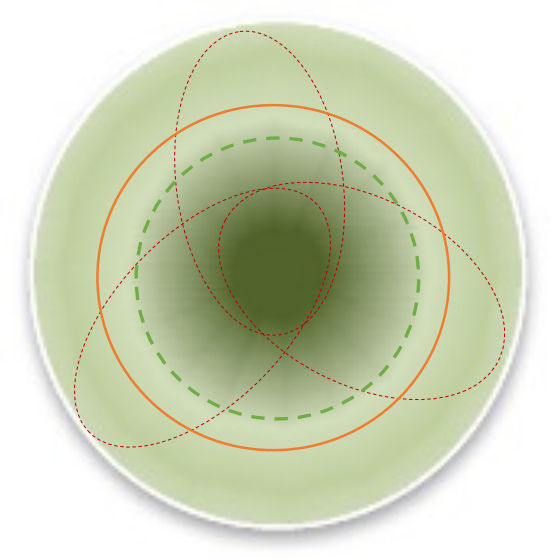

Figure 2. Disciplinary process. [Source: Authors, 2016] [10].

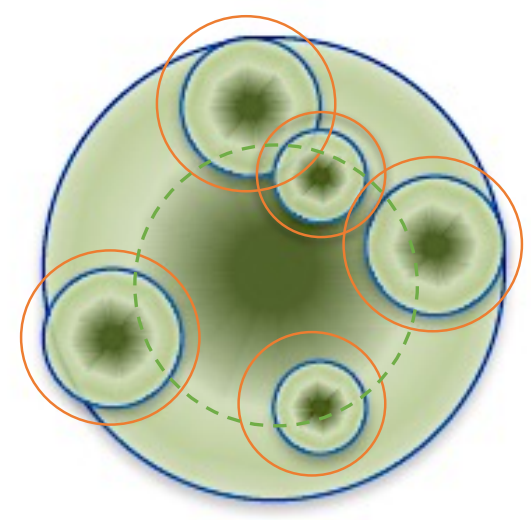

Figure 3. Interdisciplinary process. [Source: Authors, 2016] [10].

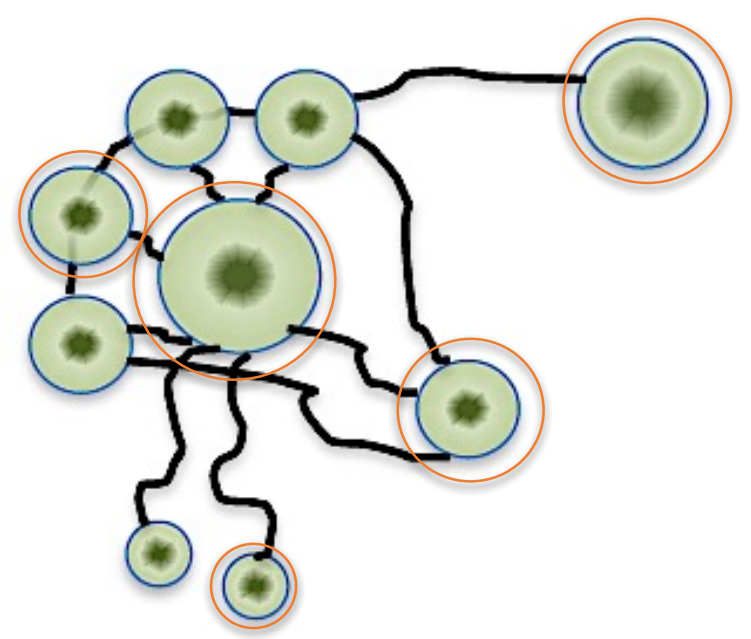

Figure 4. Multidisciplinary process. [Source: Authors, 2016] [10].

Interdisciplinary: "Process of several unrelated academic disciplines involved in a way that forces them to cross subject boundaries to create new knowledge and theory and solve a common research goal [7] [5] [10]”. 


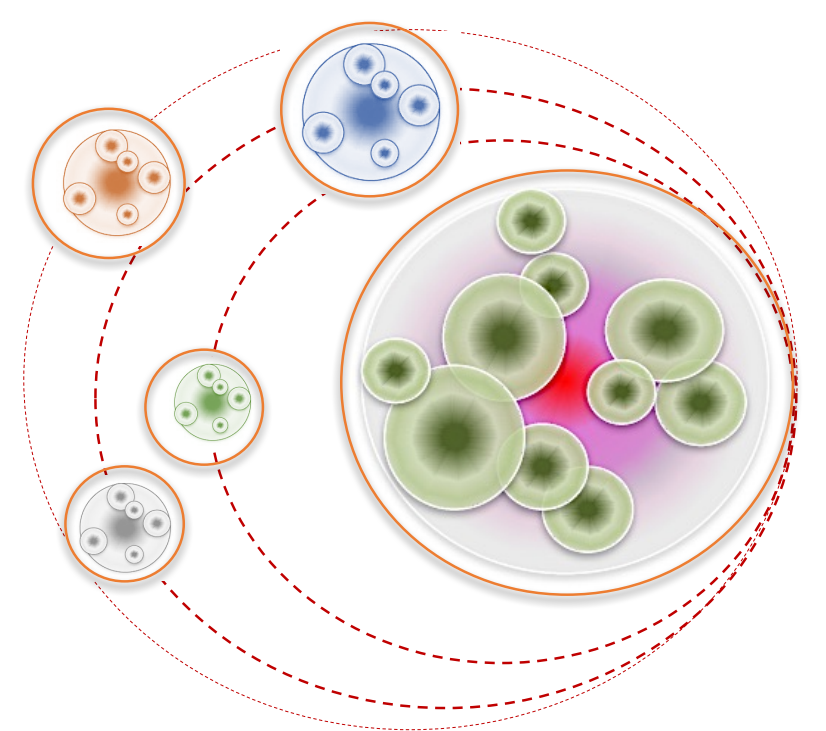

Figure 5. Transdisciplinary process. [Source: Authors, 2016] [10].

Transdisciplinary: "Process of projects that both integrate academic researchers from different unrelated disciplines and non-academic participants, to research a common goal and create new knowledge and theory. Transdisciplinarity combines interdisciplinarity with a participatory approach" [7] [5] [10].

\section{A City without a river}

Gërmia is the most beautiful part of the Pristina city, now a national park or the so called the lungs of Pristina. It is located in the region Golak plateau. It flowed from the aforementioned plateau, a rather small river Prishtevka from a place called Stalova. Pristina would be environmentally handicapped without this part of the hillside, because the entire air mass of fresh air actually comes from this direction of the mentioned mountain. By the end of the 80's it was decided then, by municipal authorities of Prishtina to be covered Prishtevka river, on behalf of epidemic conservation, general hygiene and human wellbeing [10].

According to the Master Plan Pristina (GUP-1987), the river environment was highly endangered by pollution. River Prishtevka was ranked out of class in the context of pollution from germs (coliform bacilli), with also river Sitnica into which flows Prishtevka with the function as a collector of polluted water, industrial water and waste out of all categories. 
Table 1: Pollutants by categories and municipalities - Region of Prishtina. [Source:

Cadastre of Kosovo Water Polluters], [9] [10].

\begin{tabular}{llll}
\hline Region & Municipality & $\begin{array}{l}\text { Collective } \\
\text { polluters }\end{array}$ & $\begin{array}{l}\text { Specific } \\
\text { pollutants }\end{array}$ \\
\hline \multirow{2}{*}{ Prishtinë } & Prishtinë & 12 & 7 \\
& Fushë Kosovë & 12 & 2 \\
& Drenas & 14 & 1 \\
& Podujevë & 9 & 9 \\
& Shtime & 3 & 0 \\
& Lypjan & 10 & 4 \\
& Kastriot & 7 & 1 \\
& Graçanica & 8 & 1 \\
& & & $\mathbf{2 5}$ \\
\hline
\end{tabular}

As presented in Table 1, the municipality of Prishtina are the heaviest polluted zone, primary by the collective polluters, and by specific pollutants altogether. Rivers should carry health and life, not death and disease? In the context of a rapid solution and persistence of ongoing problems, it was decided that river to be covered, the symbol of life, health provider and serenity, and opted despite the modest size and the volume of the river Prishtevka [10]. 


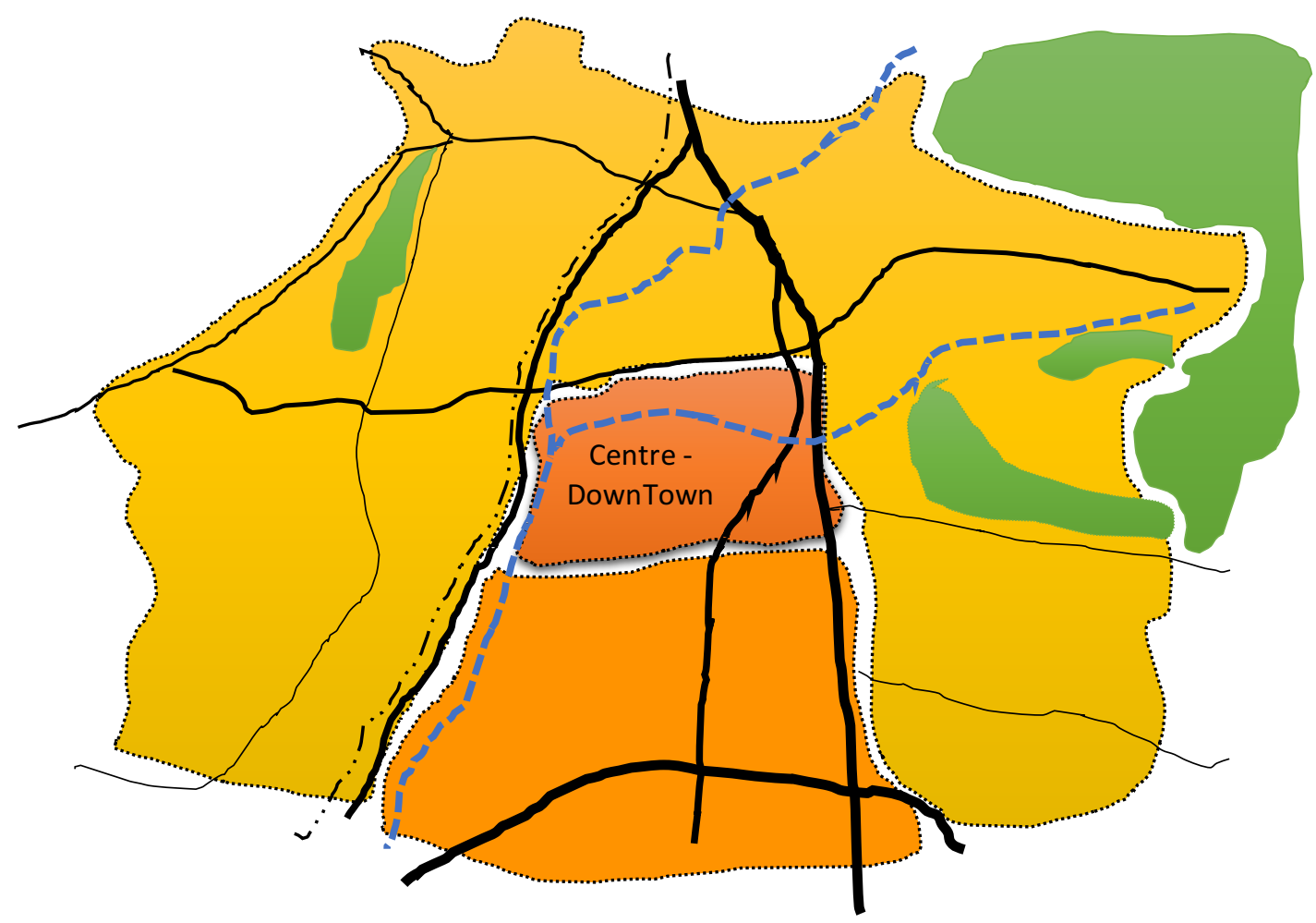

Figure 6. Routes: Prishtevka and Vellusha river's as covered, at the 80's. [Source: Authors, 2016].

From the standpoint of then, explanation of "burial" the river, maybe had a dose of the "real solution'. It is obvious that the urban culture and the culture of living style has resulted in coverage of the river, and also it was the last line of eliminating potential disease, infection, and ultimately the possible epidemic condition. However, if we remember, in the former Yugoslavia we find many labour youth actions and surely there wasn't lack of workforce, and surely it could be found optimal environmental solution for Prishtevka River, with its length of near $2 \mathrm{~km}$ ' in the city [10].

\section{A déjà vu of Prishtevka river}

Prishtina, although municipal authorities have already spent beyond a million of euros for reconstruction of infrastructure, some areas still remain without essential mainframe of infrastructure. Village Makovc, seven kilometres from the centre of Pristina, among the problems which inhabitants have is solution for sewage. In the absence of sewage, residents of the village had throwing pipes of faecal waters into the river of Prishtevka. According to Makovc residents in April, 2011: "Our sewage is in the river, however, when the level of water in river is reduced in summer period, a hard smell is formed and is sickening, a hazardous air for human health. On one side is sewer smell and on the other is waste thrown 
into the river, who also stinks. From the all of this, it is a poisoned environment in which we cannot survive."

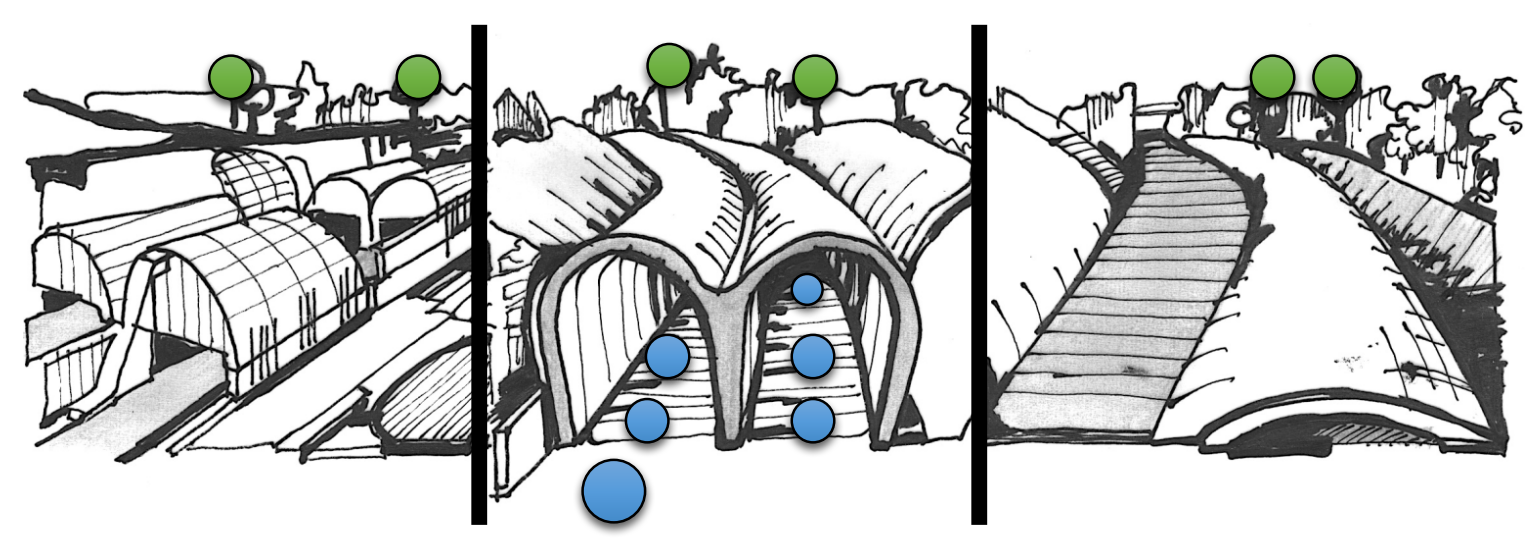

Figure 7. Sequences of covering, inearth of river Prishtevka. [Source: Authors, 2016].

In analogy, on same urban places where the water was in destitute, the necessity and philosophy was to bring water near settlements and cities, and certainly without inearth in concrete sarcophagus. indubitably the Prishtevka river, it is not even close in size and volume of the Thames or the Seine, however, implementing right environmental strategy to solve the real-life problems must encouraged, even if at first seem hopeless. It is in human nature to weighs towards better and more qualitative conditions of life, therefore it is a continuous process and aspiration towards to quality and prosperity, otherwise, the inability to cope with the problems lead to quick decisions and improvisation, to stagnation, and eventually depression prevail at the end [10].

\section{DISCUSSION}

Many authors, claim that the iteration is the key to understand the complexity of the process, Wolfram S. 2002, indicates that the iterative process, the application of simple rules, is at the heart of the mysterious ability of nature, in the production of complex phenomena and processes.

Iterations of "structure, function, and process in a given context would examine assumptions and properties of each element in its own right, then in relationship with other members of the set. Subsequent iterations would establish validity of the assumptions, then compatibilities and/or conflicts are identified and dissolved" [8].

Dissolving conflicts may require re-conceptualization of the variables involved, finally, successive iterations will produce an integrated design [8] [10]. 
The principle of iterative inquiry is reinforced by Singerian experimentalism: "There is no fundamental truth: realities first have to be assumed in order to be learned." [Singer, 1959], [8] [10].

Successive iterations would yield a greater understanding and more closely approximate to the nature of the whole. These iterations, then, are like a reverse zoom lens through which we see the system we are trying to understand as a working part of successively bigger and bigger pictures [8] [10].

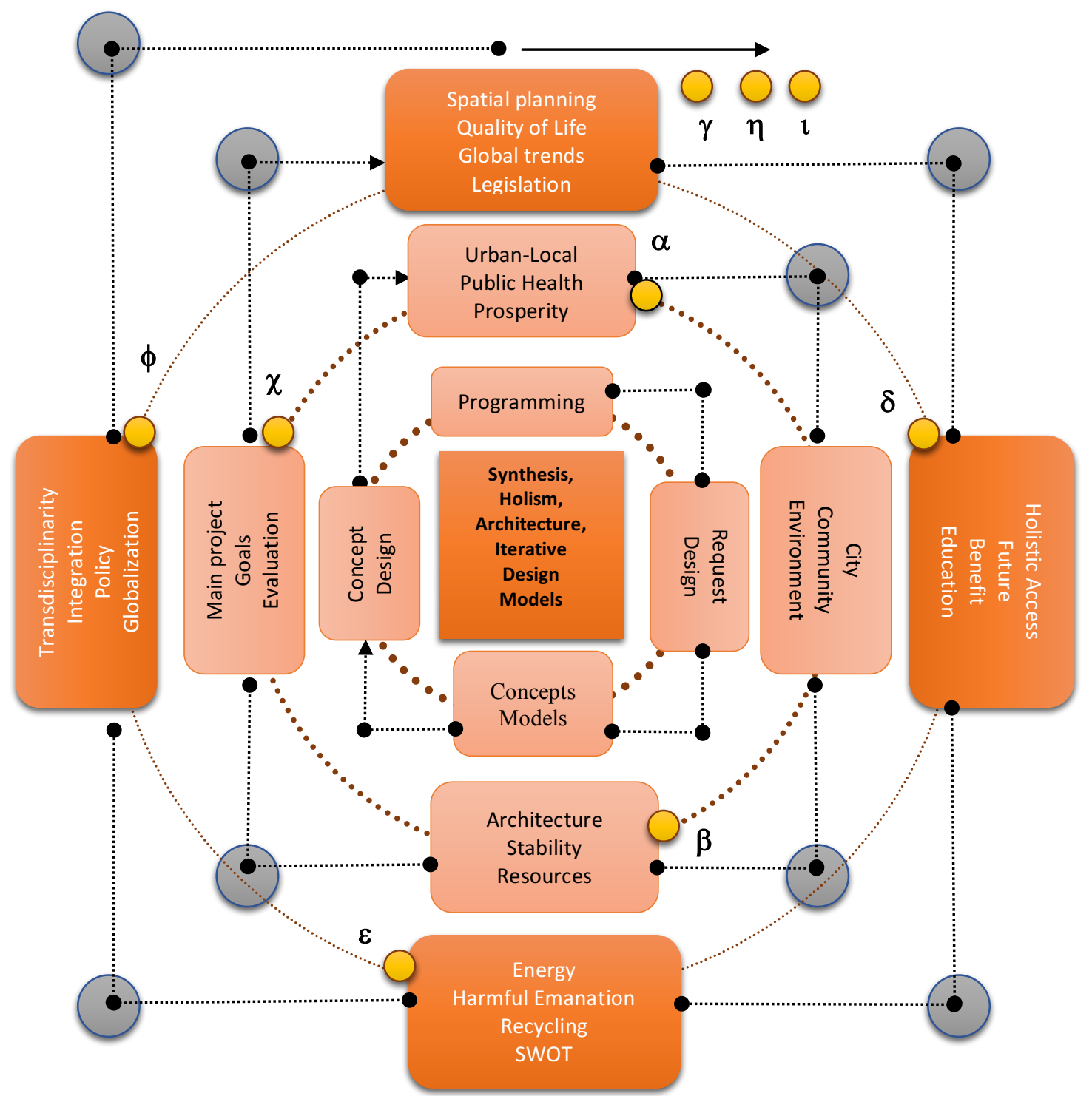

Figure 8. Complexity of iterative model: Actions to exploit transdiciplinarity on architectural design processes. Variables from different unrelated disciplines, searching a prevalent goal and solution. [Source: Authors, 2016][8].

A holistic approach to architecture, in accordance with these principles, iteration can be used as a working model in finding the best possible solution and a holistic implementation. 
If we look at architectural design holistically, we need to understand the function, composition, form, system, altogether in requiring context [10].

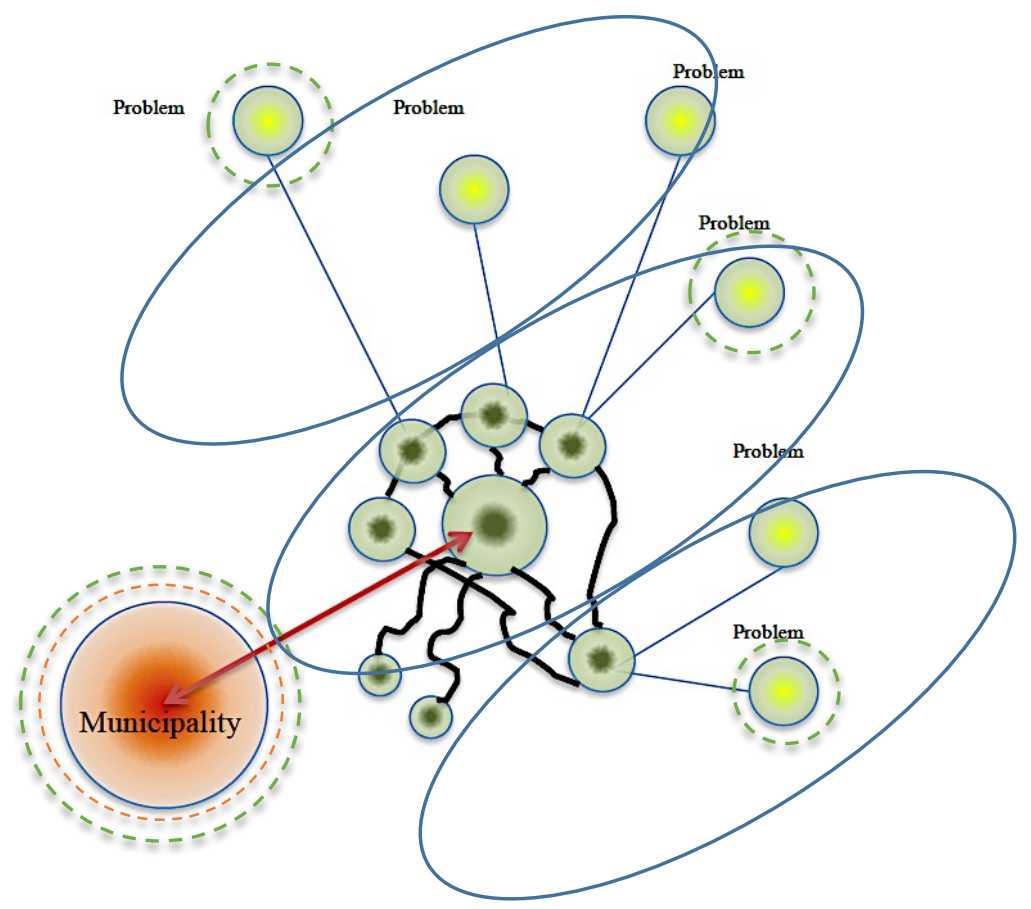

Figure 9. The actual process of problem solving. [Source: Authors, 2016] [10].

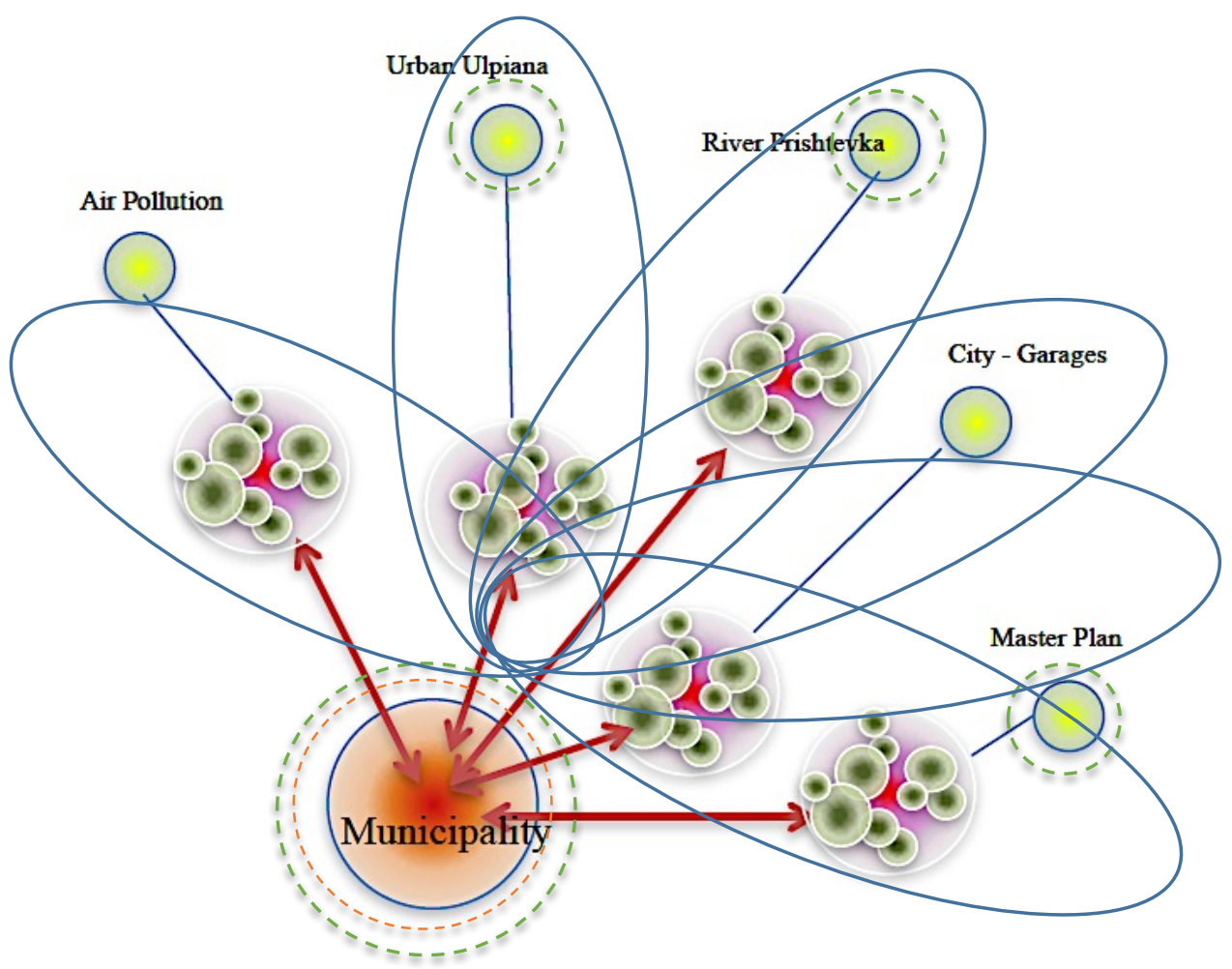

Figure 10. The preferred process of problem solving. [Source: Authors, 2016] [10]. 
The entire system and subsystem are included in solving unique problems, where participants cross the fictitious barriers, forming a specific and unique homogenized whole. Overcoming the usual and conventional boundaries of disciplines with the new findings that are not contained in any of the disciplines involved, finding unique architectural [10].

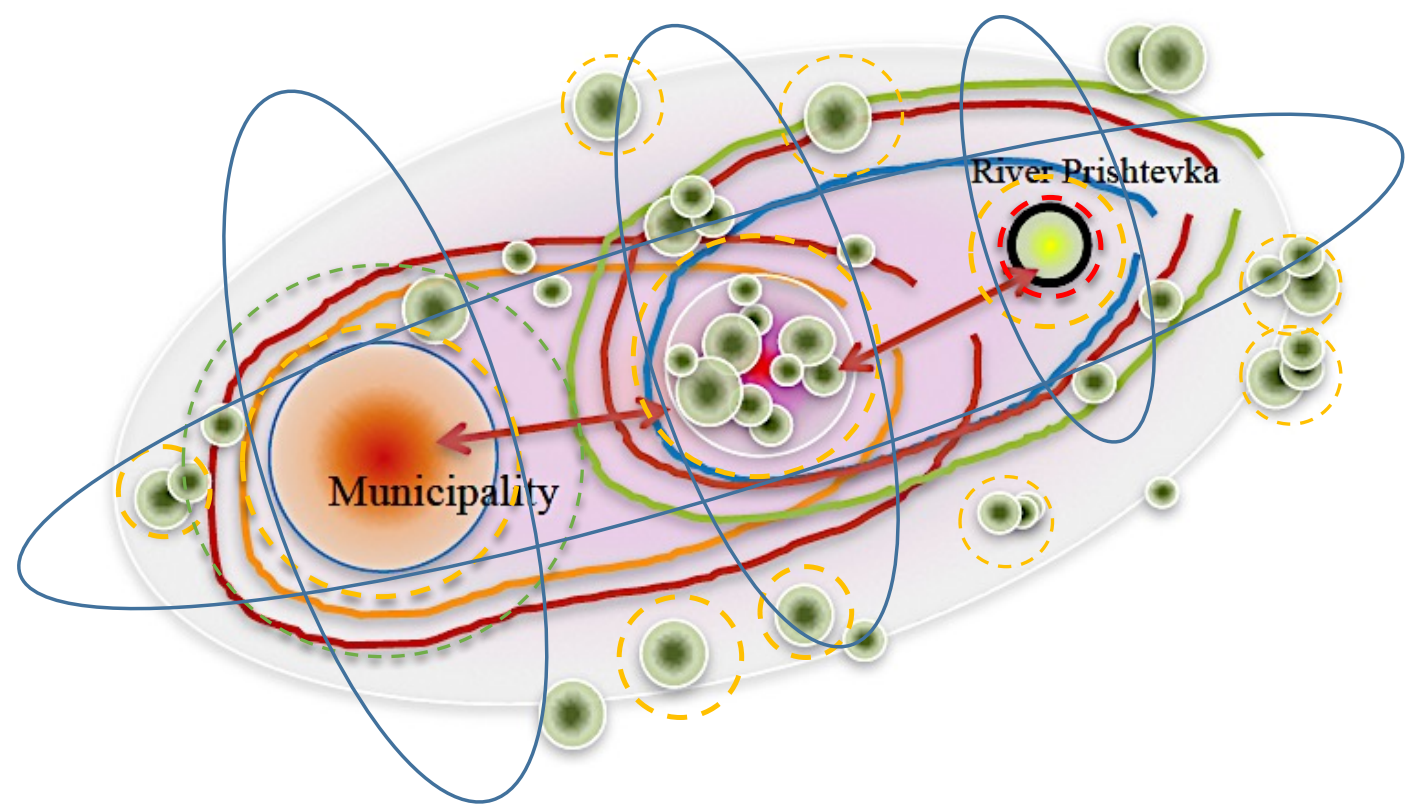

Figure 11. The iterative evolutive processes, the preferred process of problem solving, systems and subsystems. Wholeness of function, composition, form, and system in requiring context. [Source: Authors, 2016] [10].

\section{CONCLUSIONS}

Inadequate and not comprehensively solving the problem of a given task, not only drops the current problem, but also has a negative impact on future generations. Not adequately solving the specific problems of the time, results in mega problems for future generations. The current resolution of the situation with the standard members and same Commissions, formally fulfilling legal standards cannot solve the comprehensive and future challenges. Challenges, associated with the development of technology, life style, real issues and global world trends. Thus, one and the same permanent committee, the same strategy cannot respond to all specific problems faced by live city issues. Specific city problems will require specific and original solution. Hence, introduction a transdisciplinary strategy in resolving specific day to day problems allows the comprehensive features in regard to find optimal solution. The aim of this research was to accentuate the sensibility, and the necessity of taking the legal measures in introduction the establishment of specific 
professional committees, to implement cited above design strategies, which will have the right of law of expertise recommendations to authorities in the municipalities.

\section{REFERENCES}

[1]. 7Group \& Reed, B. (2009). The integrative design guide to green building. Wiley \& Sons Ltd.

[2]. Hensel, M. (2013). Performance-Oriented Architecture. John Wiley \& Sons Ltd.

[3]. Kull, K. (1998). On Semiosis, Umwelt, and Semiosphere. Semiotica, vol. 120 (3/4), 1998, pp. 299-310.

[4]. Bajçinovci, B. (2015). 3rd International Conference CICOP, BiH-The Importance of Place. Sarajevo. BiH.

[5]. Cronin, K. (2008). Transdiciplinary research and sustainability. MoRST.New Zealand. http://learningforsustainability.net/pubs/Transdisciplinary_Research and Sustainability.pdf. [Accesed: September, 2016].

[6]. Hadorn, H. G. et al. (2008). The Handbook of Transdisciplinary Research. Springer.

[7]. Tress, B; Gunther, R. \& Fry, G. (2006). Defining concepts and the process of knowledge production in integrative research. Chapter 2 in Tress, B. et al, Landscape Research to Landscape Planning - aspects of integration, education and application. Wageningen. http://atlas.uniscape.eu/allegati/02 tress.pdf. [Accesed: September, 2016].

[8]. Gharajedaghi, J. (2006). Systems Thinking. Managing Chaos and Complexity. Elsevier.

[9]. Report, (2006). Cadastre of Kosovo Water Polluters. Kosovo.

[10]. Bajçinovci, B., Jerliu, F. (2016). Integrated Design as an Evolutive Transdisciplinary Strategy. European Journal of Technology and Design, Vol. 13, Is. 3, pp. 90-98, 2016. doi: 10.13187/ejtd.2016.13.90. Academic Publishing House Researcher. RF. 